Article

\title{
Recording and Evaluating the Tangible and Intangible Cultural Assets of a Place through a Multicriteria Decision-Making System
}

\author{
Eleni Linaki ${ }^{*}{ }^{\dagger}$ and Konstantinos Serraos ${ }^{\dagger}$ \\ School of Architecture, National Technical University of Athens, 15780 Zografou, Greece; kserr@central.ntua.gr \\ * Correspondence: elenlina@mail.ntua.gr \\ † These authors contributed equally to this work. \\ Received: 28 September 2020; Accepted: 26 November 2020; Published: 2 December 2020 \\ check for \\ updates
}

\begin{abstract}
The starting point of this paper is the fact that multicriteria decision-making systems have not had the greatest impact on cultural studies, and few researchers have addressed this problem. The paper focuses on the analysis of the main object of an ongoing Doctoral thesis. More specifically, it examines the proposal of a new multicriteria evaluation based on a decision-making method. The paper intends to relate culture with multicriteria decision-making methods. This systematic review provides the direct analysis and assessment of the existing bibliographic references, and addresses a gap of knowledge in the intangible research field, identifying trends in the broader cultural heritage sector. The two basic principles of the paper are the recording and the evaluation of the cultural significance of the intangible and tangible heritage assets of a place. More specifically, the paper seeks to address a new scientific tool that initially records and - in the process—evaluates, using quantitative and qualitative criteria, specific cultural assets. Moreover, the paper outlines a new approach to the calibration-from optimal to worse- of the heritage of a place according to its significance. The purpose of the record and the evaluation is to create a ranking list of the most culturally significant tangible and intangible asset of places, in order to manage them. The design of the multicriteria method is based on a system that can be constantly updated diachronically, and can be fulfilled with new cultural assets and then re-evaluated. The explanation of the system is given through a step-by-step guide to the data analysis process, ensuring that the system has elements that are easy to access, to understand, and to use by each state actor (institution, individual, company, etc.).
\end{abstract}

Keywords: heritage; tangible culture; intangible culture; evaluation; multi-criteria system

\section{Introduction}

The aim of this research article is to further broaden the current knowledge about decision-making multicriteria systems, which are set to become a vital factor in cultural heritage. It is generally accepted that cultural heritage is a fundamental axis for Greece, but also internationally. This paper is a preliminary attempt to develop an innovative decision-making method which evaluates the cultural significance of the cultural assets of a place. The basic principle of this research is to set only the appropriate quantitative and qualitative criteria related to its significance. In this framework, other criteria—such as financial or even environmental criteria—are excluded.

A growing body of literature provides evaluation tools, through quantitative and qualitative criteria. A major defect of the literature is that the evaluation of cultural heritage refers to environmental, social, and economic quantitative and qualitative evaluation criteria. Despite this interest, no one- to the best of our knowledge- - has suggested the simultaneous evaluation of the tangible and intangible cultural assets of a place. Additionally, most studies tend to focus on tangible cultural heritage, 
and only a few have been published on the evaluation of the intangible cultural assets of the place. The protection of cultural heritage, and especially intangible cultural heritage, has emerged internationally in recent years, especially after the '2003 UNESCO Convention' about the "Definition of intangible heritage". A growing body of literature has examined culture as a parameter of risk management. Most studies have only focused on the extreme climate phenomena of natural and spatial disasters (fires, floods) [1-3]. Few studies have been published on the field of the evaluation of tangible and-especially-intangible culture. What is known about the evaluation of cultural heritage is still limited. Until now, this methodology has only been applied to cultural heritage as an evaluation parameter of a wider spatial planning project, or for the evaluation of a monument (monuments at risk, etc). Moreover, most studies tend to focus on the evaluation of the status of the materials of monuments (impact resistance, mechanical strength, fire resistance).

In the light of recent events in the evaluation and study of the tangible and intangible cultural assets of a place, this paper presents a specific literature review for the previous study, in order to illustrate the value and show the significance and innovation of the study. As the Greek-language literature reviews shows, the majority of research studies and papers concern the general interpretation of culture. Furthermore, those researches are often impractical, theoretical or historical approaches, as culture used to be examined in official educational systems (architecture, archeology, cultural management, digital culture, etc.). Those multiple interpretations of culture, through the institutions, created misunderstandings, multiple and various interpretive tools, and multiple definitions of culture. The main core of the scientific papers focuses on the utilization, protection, recording, and management of tangible culture $[4,5]$. The academic community has raised limited arguments about the theoretical research and study of tangible [6,7] and the intangible [8-10] cultural heritage. The first investigations that tried to introduce new technologies or multicriteria evaluation systems are segmented [11-15], and tended to focus on tangible cultural heritage (buildings, environment, monuments). The current tools that are used to evaluate intangible cultural heritage are unsatisfactory, and refer only to local level.

At an international level, the bibliographic review promotes theoretical research [16-19]. There are some few scientific papers related to the evaluation of cultural heritage [20-26], but most of them pinpoint tangible cultural assets. Regarding the study and the evaluation of intangible cultural heritage, the literature shows that researchers have mainly focused on linking intangible cultural heritage with new technologies (Geographical systems, 3d scanner etc. [27-29]. Despite their shortcomings, multicriteria evaluation methods have been widely applied to cultural heritage, through economic or tourism indicators.

In conclusion, the disadvantage of the current literature is primarily that there are no bibliographic references related to the evaluation of the cultural significance of the cultural assets of a place, through a multicriteria system. Additionally, previous studies failed to address a common evaluation framework and a holistic approach of the evaluation of heritage. All of the above sufficiently confirm the 'originality' of the paper and reinforce the importance of this study. These new findings reveal the national and international research gap, and the emergence of a holistic approach for the protection, recording and evaluation of cultural heritage. Multicriteria decision-making systems have become important in this field in terms of protection and conservation. Especially for intangible cultural heritage, due to the fragile nature of its assets (oral, folklore, etc.), recording and evaluation are the first steps which could ensure conservation and the protection.

\section{Materials and Methods}

This paper sheds new light on multicriteria decision-making systems. This methodology calls into question the creation of a calibration of the most significant tangible and intangible cultural assets of a place, as an integrated approach for the study of cultural heritage through a multicriteria evaluation and decision-making method. The paper is organized into two sections: recording and evaluation. This paper describes a new approach to the development of an innovative solution to the recording and evaluation of the cultural assets of a place by setting the appropriate qualitative and quantitative 
evaluation criteria related to cultural significance. The study follows the following steps: (a) a brief overview of the literature of the tangible and intangible cultural assets of places at the national and international level; (b) the multicriteria decision-making system (in this step, the study proposes a new procedure for the recording and evaluation of the cultural assets of a place); (c) the conclusions.

The aim of the literature review is to broaden the current knowledge of the definitions of the basic concepts and principals of tangible and intangible cultural heritage, as a new framework for the interpretation of the outcomes of culture and place. Additionally, the paper proceeds to the construction of the multicriteria decision-making system. This subsection begins by examining the categories of culture, in order to propose a more extensive and wide sub-categorization of the cultural assets of a place. The ambition of this sub-categorization is to formulate a wider variety of all of the cultural assets of a place. This new sub-categorization aims to create the first step of the multicriteria system (recording), which will contribute to the following step of the evaluation. In an effort to evaluate these sub-categories of cultural assets, a new methodology is outlined. As a result, in every sub-category, a variety of specific quantitative and qualitative criteria are set. The last step of the multicriteria system is the calibration of the evaluation criteria and the construction of the mathematical evaluation model. In the end, the cultural assets of a place are calibrated according to their cultural significance.

The scientific importance of this research is twofold. Primarily, this method represents an innovative categorization and record of the tangible and intangible assets of a place, and secondarily it evaluates them through a decision-making multicriteria system. This procedure is a clear advance on current methods. The proposed research lies in the fact that many uncertainties surround this field, as it concerns the not-well-considered concept of cultural heritage and its evaluation through quantitative and qualitative evaluation criteria. Therefore, the scientific value of the present research is that it contains and responds to the basic principles and the international concept of culture, which is the protection of, the rescue of, and the transition to future generations. Culture, and especially intangible cultural heritage, is in full swing, and is a sector that is related to multiple scientific fields and 'actors of protection'. This also explains the existing academic gap in the field of research and study. The diversity of the interpretations and approaches reveal the uncommon efforts to classify the cultural significance of the cultural assets of a place. The multiple categories and definitions used by international conventions need to be urgently addressed through the creation of a common method for the protection, recording and evaluation of cultural heritage. Thus, the rank classification of tangible and intangible heritage can successively, over time, protect and manage the most significant cultural assets of each place. Furthermore, the use of a multicriteria system means that it can be updated diachronically with new assets. Lastly, the user-friendly manual provides easy understanding and application.

\section{Cultural Heritage and Place}

\subsection{Tangible and Intangible Cultural Heritage}

The creation of a cultural landscape begins with an idea, which is gradually shaped into forms. The structural elements of each form are, in fact, expressed forms of energy. Collectively, for each form to exist, it must have: (a) specific energy and potential, (b) a measurable mass, (c) some space, and (d) an existence in time, that is, to have a certain duration (a start, middle and end). In other words, these four elements are the generative factors of the existence of the world, which are transformed into additional concepts (culture, place, etc.). These elements are inherent in tangible and intangible assets, and take forms and geometric dimensions in space-time as the world evolves and progresses. The world is a center around which all functions revolve. The forces of the earth are centrifugal and balanced, satisfying the basic needs of the individual, ensuring not just the need for food, but also balance, security and socialization, creating balanced places. This balance is the ecology. Ecology means respecting the limits of all elements, so that they can be developed, rested and re-developed. 
After all, sustainability and sustainable development are set in a new form of continuously-created and redefined relationships. Relationships are a constant state of bonds that change, creating analogies, similarities, affinities, interdependencies, and poles, etc., as they are articulated and arranged in the world. Their main expression comes from three successions: 1 . they are born of each other; 2 . they are attracted to each other; 3 . they balance. One relationship breeds the next and, in turn, they attract each other in an equilibrium state. Relationships are born between people, between man and nature, between nature and society, between society and culture, etc.: they are interrelated, continuous, new or older, and are related to man, nature and culture. These relationships create natural and human ensembles, places, landscapes, and societies [30].

In this perspective, every city has a past and a form, and it's a new experience both tangible and intangible [31]. Every community creates a culture to show, to protect and to manage. Culture and cultural heritage act in everyday life [32]. Beginning by the theory that culture is much more than the legislation, the main conventions, and the declarations of a society, culture is everywhere [33]. In other words, culture is an ongoing process that leaves significant traces without affecting the progress of communities and their futures. Cultural heritage is the inherited culture that communities tend to preserve in order to transfer knowledge to future generations. Culture is a completely expanded and tricky concept that is constantly being renewed and revised, and it incorporates new inputs of interpretation from mankind, art, folklore, and architecture, etc. [34]. Besides this, every community is an ensemble of speech and myth, where each individual creates its own speech and myth, at a reasonable and spiritually-corresponding level. In other words, they create an identity [35]. Cultural identity is something wider than culture; is the result of a collective historical experience of many fields, creating a common set of values. The coexistence of the people, in which these values and the social consciousness are composed, is the creation of a man-made landscape: a city [36]. As a space of interaction with and experience of a set of values, a city is always an "on the move" concept, which brings together citizens and, through their co-operation, helps to develop the individual consciousness that leads to the collective consciousness of the place [37].

Every city is a place filled with motivation, emotions and people, and every city has a past, a present, and a future expressed through time and energy. In this concept of the three parameters (time, place and energy), the rhythm of a place is grouped into programmed events, cultural assets, and history, etc., and the above-mentioned triptych interferes with alternations, repetitions, etc., through the dynamic of each place [38,39]. Thus, urban spaces are transformed, mainly through actions, into new spaces that are completely mutated. Static urban space is not always the same and commonly used. It gives its place to new events, structures, and explorations, new possibilities of opening, producing new rules and fluxes of interaction within these constantly-changing urban entities, affecting the vitality, publicity and sharing of urban spaces [39]. The above description refers to the city, and automatically creates an inner and outer contour space, in the form of repeatability and ephemerality, etc. Each form has a shape and limits of its content. Tangible forms are all dimensional, as intangible forms are non-dimensional. Each form is a place, expressed mainly through the community. Tangible cultural assets concern material assets, such as buildings, monuments etc. The term "intangible cultural heritage" is considered to represent an "English translation" of the Japanese expression "mukei bunkazai" [40]. In the Western world, the word 'intangible' means: a/ something that does not have a material existence, i.e., the spirit is immaterial, yielding and intangible. b/ (For a material body) very transparent, ethereal and immaterial, i.e., the intangible forms of Byzantine hagiographies.

In a deeper analysis of the above, each place-or even the world-is divided into three main expressions of resources: natural resources (flora, seas, hills, etc.), man-made resources (buildings, roads, schools), and intangible resources (customs, folklore, myths). Through these three expressions, there is a common way of setting all the goals, priorities and decisions for each society's future. They are the initial components for the evolution of the future. For its smooth operation, the world-through natural, human and intangible resources-sustains the continuation of the transmission of a movement, in the 
sense that they are preserved today only if they are in an endless relation with their perpetual creative force. They are not self-propelled, but they are moved and move each other, creating a chain of sequential movements until the end [41]. The main correlation of intangible and tangible (manmade and natural) culture is the realization that culture, as a conquest, is always at the same time immaterial and material. The separation of the two concepts concerns mainly the reasons of understanding and legal protection. Tangible heritage has a variety of legislations, texts, and conventions, which began after the Second World War, as a huge number of monuments, treasures and cultural assets were lost or destroyed. [42,43]. The first legislation text about intangible culture is the UNESCO convention on the 'Safeguarding of Intangible Cultural Heritage in 2003' [44], which defines intangible cultural heritage as: "practices, representations, expressions, knowledge and techniques - as well as the tools, objects, handicrafts and cultural sites associated with and which communities, groups and, where appropriate, individuals recognize as part of their cultural heritage" (Article 2 (1)). In the context of the present study, this separation of tangible and intangible culture (Figures 1 and 2) will be followed for reasons of understanding, and the easy management and organization of the categories of the cultural assets of a place [45].

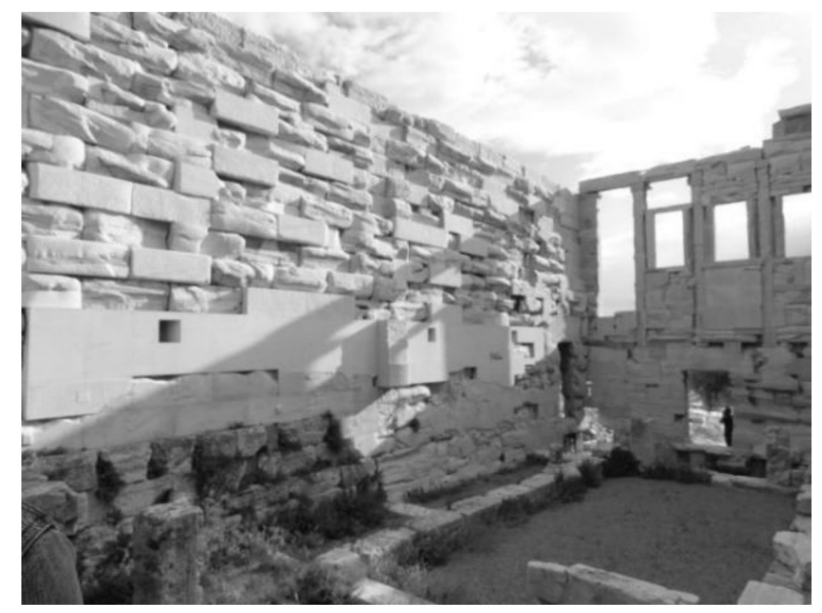

Figure 1. Tangible cultural heritage (the Monument of Erechtheion, Acropolis).

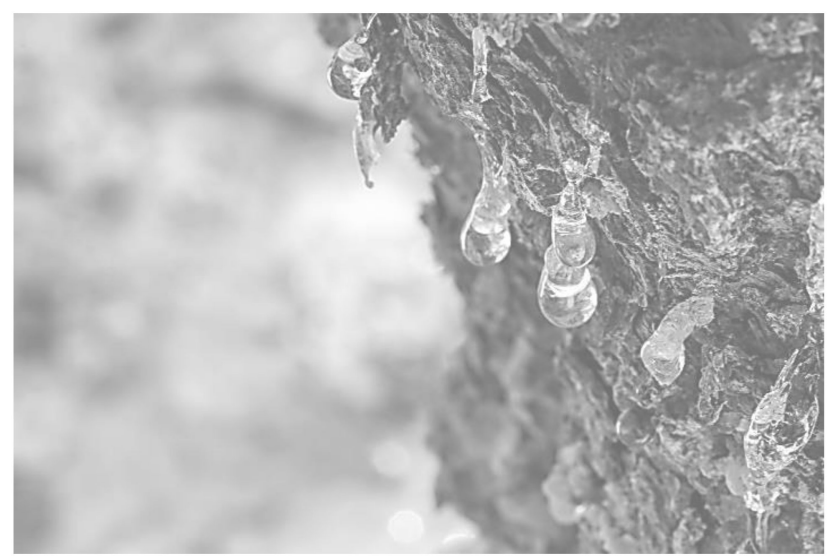

Figure 2. Intangible cultural heritage (Traditional Masticulture in Chios).

\subsection{Categories of the Cultural Assets of a Place}

In this subchapter, the article attempts to organize the categories and sub-categories of tangible and intangible cultural assets in order to create a complete record of them. Subsequently, the paper is organized as a record, from general to special. Explanatorily, the paper proposes the development of the categories of culture from general to special, from the wider category to specific ones. The sequential description of the categories from the general to the specific is described in Figure 3. Firstly, the paper 
examines the two main cultural categories: 'Tangible' and 'Intangible', which are from this point on referred to as 'Main cultural assets'. As mentioned below, each place (or the world) is divided into three main expressions of assets: natural assets (flora, seas, hills, etc.), man-made assets (buildings, roads, schools), and intangible assets (customs, folklore, myths) $[46,47]$. Following this finding, we decided to use of these three categories (natural assets, man-made assets, and intangible assets) as the second more extensive category, under the name 'Assets'. The third category is called 'Categories', and the last is called 'Records'.

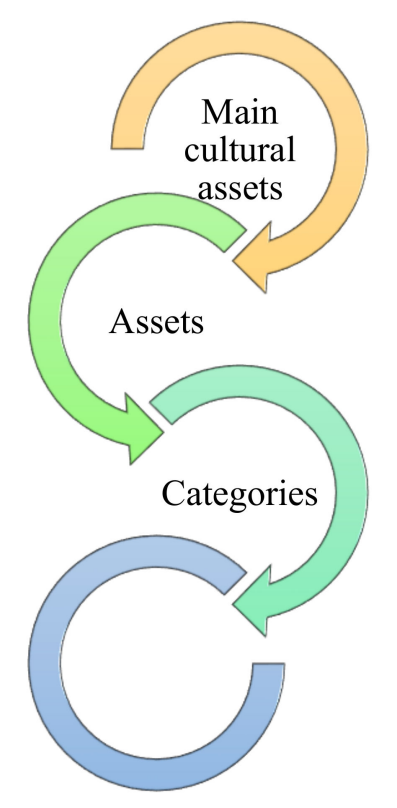

Figure 3. Sequential description of 'Records'.

Clarifying the above, the third categorization, called 'Categories' consists in a sub-categorization of 'Assets'. For example, for the Natural assets (categorization 'Assets') the 'Categories' are shown in the below Table 1.

Table 1. Example of categories.

\begin{tabular}{cc}
\hline Assets & Categories \\
\hline \multirow{3}{*}{ Natural assets } & 1. Morphology \\
\cline { 2 - 2 } & 2. Blue surfaces \\
\cline { 2 - 2 } & 3. Biodiversity \\
\hline
\end{tabular}

Natural assets consist of three more descriptive sub-categories. Additionally, the same sub-categorization is used for the last category of culture, the 'Records'. The 'Records' consist in a sub-categorization of the 'Categories'. If Biodiversity is the 'Category', the 'Records' are as shown in Figure 4.

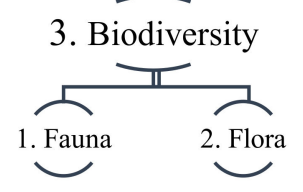

Figure 4. Categories of Biodiversity. 
To summarize the above in the below Table 2, a detailed description is given, through the detailed description of the final 'Record' flora.

Table 2. Detailed description of Flora.

\begin{tabular}{cccc}
\hline Main Cultural Assets & Assets & Categories & Record \\
\hline Tangible cultural assets & Natural assets & Biodiversity & Flora \\
\hline
\end{tabular}

The design of this method is based on repeating patterns. The same steps of sub-categories are used for each cultural asset, in order to record the whole cultural heritage of a place and identify the more descriptive records. After this step, all of the categories and sub-categories create the first step of the multicriteria system. In the end, the paper presents the most extended and describable categories of cultural heritage, called 'Records'. We decided that the best method for this study was to gather all of the possible categories and sub-categories of tangible and intangible cultural heritage of a place. 'Records' is the category in which quantitative and qualitative evaluation criteria will be applied in the second step of the evaluation of the multicriteria decision-making system [48].

\section{Development of the Multicriteria Decision-Making System}

The remarkable feature of the evaluation is the multicriteria decision-making system. As mentioned below, our study provides the framework for a new way to record and evaluate the cultural assets of a place. Evaluation is increasingly becoming a vital factor in heritage. The key point of this chapter is the subcategory named 'Records'. This subcategory is recognized as being the most important and remarkable feature of record. With this in mind, in this chapter, the paper tries to set the appropriate qualitative and quantitative criteria for each Record. In order to identify the appropriate ones, the paper examines and proposes the steps below. After a literature review of the methodologies of decision-making processes and the most suitable decision-making methodology called MAUT (Multiple Attribute Utility Theory) is selected. Multi-attribute utility theory identifies the relevant objectives for any given decision. Where a decision is typified by multiple objectives, it can be difficult to quantitatively compare these objectives one against another. In order to provide insight into this problem, a utility function is assessed for each of the relevant objectives. This allows an appropriate multiple-objective utility function that is then used to identify the trade-offs and compare the various objectives in a consistent manner [49]. A striking feature of the decision-making methodology of MAUT is the 'Multiple-criteria evaluation problem'. The evaluation problem is set by the 'decision maker', and it describes the aim of the multicriteria system. In the proposed research, the author of this article is formed as a 'decision-maker', and set the 'evaluation problem', which is "The calibration of the most significant tangible and intangible cultural assets of a place". After the completion of the first step, in each 'Record', either quantitative or qualitative evaluation criteria, related to cultural significance, are placed. A major challenge of the study is that any other evaluation criteria (e.g., tourism or economic criteria) are deemed unsuitable for use. Due to the literature gap of suitable criteria, this specific area of qualitative and qualitative criteria has remained unclear. In this context, the paper seeks to identify the suitable criteria, through multiple tests, in order to select the appropriate ones. As such, in the end of this procedure, a set of specific quantitative and qualitative criteria are developed in each 'Record'. The number of the quantitative or qualitative criteria differ, and concern the nature and structure of each Record.

Therefore, the second step (Evaluation) focuses on the sequential steps given in Figure 5.

Regarding the evaluation criteria, the initial philosophy of the system is that, in each 'Record', five evaluation criteria are set. According to the main principal of the decision-making process, the evaluation criteria must be odd numbered, in order to calculate the 'average price' [50]. Therefore, as mentioned above, five either quantitative or qualitative criteria are applied in each 'Record' [51]. After some descriptive data and screening test results, the evaluation criteria are calibrated (step: 
Calibration 0-4). For the further understanding of the above, the below Table 3 describes the evaluation criteria, for Record 'Flora'.

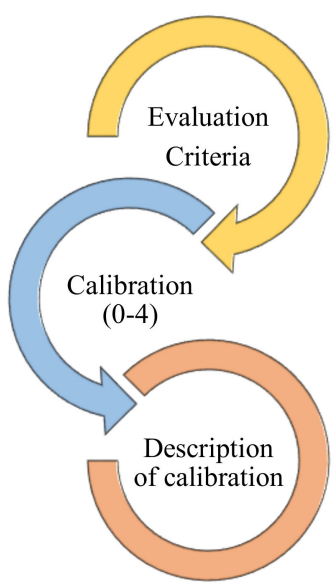

Figure 5. Sequential description of Evaluation.

Table 3. Description of the evaluation criteria.

\begin{tabular}{cc}
\hline Record & \multicolumn{1}{c}{ Evaluation Criteria } \\
\hline \multirow{3}{*}{ Flora } & $\frac{\text { 1. Level of maintenance of the initial existence of species }}{\text { 2. Existence of important habitats }}$ \\
\cline { 2 - 2 } & 3. Uniqueness of protected species \\
& 5. Vonnection with the history and tradition of the place \\
\hline
\end{tabular}

As the Table 4 shows, the selected criteria for 'Flora' are both qualitative and quantitative. The last step of the evaluation is the 'Description of calibration'. This means that, for each of the five evaluation criteria, a $0-4$ scale is subscribed. This detailed description ensures and provides a common interpretation and evaluation of the system. An additional commitment of the calibration system is that it follows the logic from the worst to the best. Consequently, for each calibration value ' 0 ' is insignificant and ' 4 ' is extremely significant, with intermediate values [52]. Particularly, if a monument is in a dilapidated condition, it receives from all of the users of the system a value of 0 . In the context of this assumption, the selection of the criteria and the manner of their expression is made so that they can be calibrated and evaluated from the negative to the positive. Furthermore, the detailed description helps the respective user or researcher to understand the decision-making system, and ensures the system's reliability. In explanation of the above, the below table shows the description of the calibration of one of the above evaluation criteria of Flora ('Variety of species').

After completing this step, the entire Table 5 of «Records» has five values in the column of 'Selection $0-4$ '. In the following table, for the Record 'Flora', random values of the five criteria are recorded, in order to understand the last step of the multicriteria system, which is the construction of the mathematical model.

The last step of the multicriteria decision-making system is the creation of the ranking list of the cultural assets of a place. As such, in the last column, the «average price» is calculated by taking the sum of the values of the five evaluation criteria and dividing it by the number of criteria (5) being examined. For the example of flora, the 'average price', is

$$
\frac{0+3+2+2+3}{5}=2
$$


Table 4. Description of calibration of Flora.

\begin{tabular}{|c|c|c|c|}
\hline Record & Evaluation Criteria & Description of Calibration & Selection from $0-4$ \\
\hline \multirow{5}{*}{ Flora } & \multirow{5}{*}{ 1. Variety of species } & 0: Up to 10 different species of flora are identified & \multirow{5}{*}{0 (random value) } \\
\hline & & 1: Up to 20 different species of flora are identified & \\
\hline & & 2: Up to 50 different species of flora are identified & \\
\hline & & 3: Up to 100 different species of flora are identified & \\
\hline & & 4: More than 100 different species of flora are identified & \\
\hline
\end{tabular}

Table 5. Description of the values of the five criteria of Flora.

\begin{tabular}{llc}
\hline \multirow{2}{*}{ Record } & \multicolumn{1}{c}{ Evaluation Criteria } & Selection from 0-4 \\
\hline \multirow{3}{*}{ Flora } & 0: Up to 10 different species of flora are identified & 0 \\
\cline { 2 - 3 } & 1: Up to 20 different species of flora are identified & 3 \\
\cline { 2 - 3 } & 2: Up to 50 different species of flora are identified & 2 \\
\cline { 2 - 3 } & 3: Up to 100 different species of flora are identified & 2 \\
\hline 4: More than 100 different species of flora are identified & 3 \\
\hline
\end{tabular}

Therefore, there is an 'average price' for each record. In the end, the whole calibration of the tangible and intangible assets of each place creates a ranking list. This list is based on the values of the average price. For example, if flora, a monument, folklore music and fauna have the 'average prices' of 4, 2, 3 and 1, respectively, that means that Flora is more cultural significant than folklore, music, etc., and the ranking list is:

1. Flora (average price: 4),

2. Folklore music (average price: 3 ),

3. Monument (average price: 2),

4. Fauna (average price: 1 ).

The base point of the proposed multicriteria system is the creation of an open multicriteria system. In particular, its importance is threefold. First, it is not limited to local use, but has a universal character. Secondly, it can evaluate and calibrate the most culturally significant assets for each place in order to protect and manage them. Thirdly, it can be continuously and over time fulfilled with new cultural assets and re-evaluated.

\section{Discussion}

As culture, and especially the intangible culture of the places, shows fragility and tends to disappear due to natural (decay, oblivion, natural disaster) or artificial (wars, deliberate disasters) disasters, this paper is an overview of the need to protect and save the intangible and tangible cultural assets of a place. For this reason, the scientific value of this paper is the extensive and multilevel recording and evaluation of the cultural significance of intangible and tangible cultural assets through a decision-making multicriteria system. The value of this step lies in the fact that, in a digital environment, it can crystallize and save, through the record, the existing cultural assets of the places. The second contribution to science is the evaluation of intangible and tangible cultural assets by the introduction of calibrated qualitative and quantitative indicators, in an attempt to evaluate and rank cultural assets. This paper sheds new light on the creation and proposal of a common effort to interpret culture, through a step by step multicriteria system. The detailed explanatory structure of the decision-making multicriteria system makes it understandable and easy to use for each user.

This paper has highlighted the importance of the evaluation of the intangible and tangible cultural heritage of a place. Our study provides the framework for a new way to classify and rank the cultural 
assets of a place by their cultural significance. As mentioned above, in the specific subject of the proposed research project there is currently not a satisfactory level of knowledge, as this incorporates a new methodology of recording and evaluation which has not yet been extensively and systematically analyzed in a national and international context. The investigation into this area is still in progress, and seems likely to confirm our hypothesis. This research could be a useful aid for decision makers and a strong axis for new research papers.

This could eventually lead to development of new ways of viewing, interpreting, quantifying and classifying of the cultural assets of a place. The findings of the research have important managerial implications. The present paper aims to validate those new findings regarding cultural heritage. The results of the research may improve the knowledge of the recording and evaluation of cultural heritage. Additionally, the aim of this study is to help the various stakeholders of heritage (state actors, ordinary users, local communities, international organizations, etc.). A further important implication is that the system can be constantly updated and re-evaluated. The prospect of being able to re-evaluate the tangible and intangible cultural assets of a place serves as a continuous impulse for future research.

Cultural heritage empowers cities and regions to strengthen their policies and initiatives, as well as to develop innovative solutions to preserve their assets. As such, this system will help and empower the various national and international stakeholders. More specifically, the qualitative and quantitative criteria of the decision-making system can be used as an example for the evaluation of the cultural assets of the places in their proposals in international institutions as 'historic cities' of UNESCO or 'intangible heritage' of the World, etc. Especially for the intangible cultural assets, the criteria of the system can be a common evaluation framework for the 'List of Intangible Cultural Heritage of UNESCO', or the 'National Index', etc., at a universal level.

\section{Conclusions}

This paper attempted to develop a new multicriteria decision-making system for cultural significance, using quantitative and qualitative evaluation criteria. The aim of this study was to formulate a new methodology for the evaluation of culture. This work highlighted the terms of tangible and intangible cultural assets in order to redefine and classify them by the concepts of the environment, humanity, and society into the context of culture and heritage. This may be considered a further validation for governments, groups, or operators of culture, or anyone involved in cultural management.

Additionally, the importance of the proposed research is that:

A. The paper outlines an innovative solution for the protection and evaluation of the cultural heritage of places. In addition, these findings provide additional information about both tangible and intangible cultural assets.

B. The value of our contribution lies in the proposed system. Our study provides the framework for a new way to evaluate the cultural heritage of each place, nationally and internationally. Additionally, this new evaluation system can be easily fulfilled and shared, among the respective users (governments, organizations, and ordinary users).

C. Collectively, our results appear to be consistent with the evaluation criteria. The use of quantitative and qualitative criteria provides a powerful methodology for the evaluation of culture, as it describes new knowledge or ideas based on original research. The proposed research may provide a useful resource for future studies.

D. Finally, the most important impact of the research is the creation of a new innovative multicriteria decision-making system. The broad implication of the present research is that it records and evaluates culture, and especially intangible culture, which so far has not be sufficiently studied, particularly at a scientific level. 
Author Contributions: Conceptualization: E.L. and K.S.; methodology: E.L. and K.S.; software: E.L. and K.S.; validation: E.L. and K.S.; formal analysis: E.L. and K.S.; investigation: E.L. and K.S.; resources: E.L. and K.S.; data curation: E.L. and K.S.; writing-original draft preparation: E.L. and K.S.; writing-review and editing: E.L. and K.S.; visualization: E.L. and K.S.; supervision: E.L. and K.S.; project administration: E.L. and K.S.; funding acquisition: E.L. and K.S. All authors have read and agreed to the published version of the manuscript.

Funding: The manuscript has received no external funding.

Conflicts of Interest: The authors declare no conflict of interest.

\section{References}

1. Guzmán, P.; Roders, A.A.P.; Colenbrander, B.B. Measuring links between cultural heritage management and sustainable urban development: An overview of global monitoring tools. Cities 2017, 60, 192-201. [CrossRef]

2. Giove, S. Economic forecasting with tangible and intangible criteria: The analytic hierarchy process of measurement and its validation, an application of Multicriteria Decision Making to build heritage: The case of Calcutta, Impact of culture on tourist decision-making styles. J. Multi-Criteria Decis. Anal. 2010, 17, 85-99.

3. Jamal, T.; Hill, S. Developing a framework for indicators of authenticity: The place and space of cultural and heritage tourism, Long life monitoring of historical monuments via wireless sensors network. Asia Pac. J. Tour. Res. 2004, 9, 353-372. [CrossRef]

4. Alexandri, E. Cultural heritage-Management. In Cultural Renaissance of 19th Century Athens; Ion: Athens, Greece, 2015.

5. Papoulias, E. The Management of Cultural Heritage in Greece; Politia: Athens, Greece, 2012.

6. Gialoura, A. Material culture: Anthropology in the Land of Things; Politia: Athens, Greece, 2012.

7. Economou, A. Tangible Culture: Theory, Methodology, Exploitation; Papazisi: Athens, Greece, 2014.

8. Kanelatou, A. UNESCO and Intangible Cultural Heritage: Critical Study Regarding the Inclusion of Data in the Hellenic National Depository; Postgraduate Work; Hellenic A-Open University: Athens, Greece, 2017.

9. Korka, T. Intangible Cultural Heritage - Comparative Law Study; Sakkoulas: Athens, Greece, 2020.

10. Tzavara, I. Intangible Cultural Heritage; Ministry of Culture and Tourism: Athens, Greece, 2018.

11. Tsipis, F.S. Utilization of New Internet Technologies and Mobile Device Applications for the Promotion and promotion of the Intangible Cultural Heritage; Postgraduate Work; University of Patras: Patras, Greece, 2018.

12. Ktori, M. Lefkara Lace: Educational Approaches to ICH in Cyprus. Int. J. Intang. Herit. 2020, 12.

13. Aristeidou, A.; Stavrakis, E.; Chrysanthou, Y. Intangible cultural heritage: Recording of cypriot traditional dances and electronic ways of learning them. In Proceedings of the EUROMED Conference, Volos, Greece, 24-26 September 2015.

14. Chatzigrigoriou, P. Development of a Multi-Criteria System of Digital Management of Remarkable Buildings and Ensembles Based on Data and GIS: The Case of the Historical Site of Ermoupolis. Ph.D. Thesis, National Technical University of Athens, Athens, Greece, 2013.

15. Karadimou, G. Definition of landscape evaluation indicators of the Greek area. In Proceedings of the 10th International Geographical Conference, Thessaloniki, Greece, 7 November 2014.

16. Bouchenaki, M. The interpedency of the tangible and intangible cultural heritage. In Proceedings of the ICOMOS 14th General Assembly and Scientific Symposium, Victoria Falls, Zimbabwe, 27-31 October 2003.

17. Ruggles, F.; Silverman, H. From Tangible to Intangible Heritage; Springer: Berlin, Germany, 2009; pp. 131-142.

18. Lenzerini, F. Intangible Cultural Heritage: The Living Culture of Peoples. Eur. J. Int. Law 2011, 22, 78-86. [CrossRef]

19. Vecco, M. A definition of cultural heritage: From the tangible to the intangible. J. Cult. Herit. 2010, 11, 321-324. [CrossRef]

20. Bottero, M. Evaluating Tangible and Intangible Aspects of Cultural Heritage: An Application of the PROMETHEE Method for the Reuse Project of the Ceva-Ormea Railway': Integrated Evaluation for the Management of Contemporary Cities; Springer: Berlin, Germany, 2018; pp. 285-295.

21. Dragonas, J.; Doulamis, A.; Ioannidis, C.; Klein, M.; Ioannides, M. Modelling of Static and Moving Objects: Digitizing Tangible and Intangible Cultural Heritage. Mix. Real. Gamification Cult. Herit. 2017, 3, 567-589. [CrossRef]

22. Kioussi, M.; Karoglou, M.; Labropoulos, K.; Bakolas, A.; Moropoulou, A. Integrated documentation protocols enabling decision making in cultural heritage protection. J. Cult. Herit. 2013, 14, 141-146. [CrossRef] 
23. Scott, C. Measuring the immeasurable: Capturing intangible values. In Proceedings of the Marketing and Public Relations International Committee of ICOM (International Council of Museums), Brno, Czech Republic, 19 September 2011.

24. Baglieri, M.; Chiesa, V.; Manzini, R.; Grando, A. Evaluating Intangible Assets: The Measurement of R\&D Performance. SSRN Electron. J. 2001, 19, 23-38.

25. Bruschi, V.M.; Cendrero, A. Geosite evaluation: Can we measure intangible values. Ital. J. Quat. Sci. 2005, 18, 291-304.

26. Ioannides, M.; Athanasiou, V.; Chatzigrigoriou, P.; Papageorgiou, E.; Leventis, G.; Nikolakopoulou, V.; Sovis, C. Immersive Digital Heritage Experience with the Use of Interactive Technology; Springer: Berlin, Germany, 2016; pp. 43-52.

27. O'Lear, S.; Diehl, P.F.; Frazier, D.V.; Allee, T.L. Dimensions of territorial conflict and resolution: Tangible and intangible values of territory. GeoJournal 2005, 64, 259-261. [CrossRef]

28. Severo, M.; Venturini, T. Intangible Cultural Heritage Webs Comparing national networks with digital methods. SAGE J. 2016, 18, 341-364. [CrossRef]

29. Mamaloukos, S. Cultural Heritage: Sero Time; Hellenic Society of Enviroment and Culture: Athens, Greece, 2008.

30. Moraitis, K. The Art of Landscape: A Cultural Overview of Modern Local Views and Conturations; Kallipos: Athens, Greece, 2015.

31. Pikionis, D. Texts; National Bank Educational Foundation (MIET): Athens, Greece, 2014.

32. Sinisoglou, N. Gnostic. Elements of Philosophy. Theophilos Kairis; Cairo Library: Alexandria, Egypt, 2008.

33. Aykan, B. Patenting' Karagöz: UNESCO, nationalism and multinational intangible herit-age. Int. J. Herit. Stud. 2015, 21, 949-961. [CrossRef]

34. Harvey, D.C. Heritage Pasts and Heritage Presents: Temporality, meaning and the scope of herit-age studies. Int. J. Herit. Stud. 2001, 7, 319-338. [CrossRef]

35. Antchak, V. City rhythms and events. Ann. Tour. Res. 2018, 68, 52-54. [CrossRef]

36. Mylonopoulos, D. The International Protection of the World Natural Heritage in a Period of Hostilities; Law and Nature: Athens, Greece, 2007.

37. Linaki, E. Intangible and Tangible Cultural Resources of Ano Syros. A Model Urban Study. Bachelor's Thesis, Aristotle University of Thessaloniki, Thessaloniki, Greece, 2016.

38. Stefanou, J. The Physiognomy of the Greek City; University Press, NTUA: Athens, Greece, 2000.

39. Terzić, A.B.Z.; Ćurčić, N. Common Histories, Constructed Identities: Intangible Cultural Heritage and the Rebranding of Serbia. Int. J. Intang. Herit. 2015, 10, 101-124.

40. Terkenli, T. The Cultural Landscape; Papazisi: Athens, Greece, 1996.

41. Lavier, Z. Chinese Acupuncture: History, System, Practice; Fiery world: Athens, Greece, 1988.

42. Harrison, R. Forgetting to remember, remembering to forget: Late modern heritage practic-es, sustainability and the 'crisis' of accumulation of the past. Int. J. Herit. Stud. 2013, 19, 579-595. [CrossRef]

43. Heller, A. Cultural Memory, Identity and Civil Society; Academia: Leeds, UK, 2001; pp. 139-143.

44. UNESCO. Text of the Convention for the Safeguarding of the Intangible Cultural Heritage; UNESCO: Paris, France, 2003.

45. Pocock, C.; Collett, D.; Baulch, L. Assessing Stories before Sites: Identifying the Tangible from the Intangible, School of Arts and Communication. Master's Thesis, University of Southern Queensland, Toowoomba, Australia, 2014.

46. Solanilla, L. The Internet as a Tool for Communicating Life Stories: A New Challenge for "Memory Institutions". Intag. Herit. 2008, 3, 45-49.

47. Nijkamp, P. A Survey of Methodes for Sustainable City Planning and Cultural Heritage Management; Research Memorandum; Serie Research Memoranda 0050; VU University Amsterdam, Faculty of Economics, Business Administration and Econometrics: Amsterdam, The Netherlands, 1998; p. 50.

48. Klopp, J.; Petretta, D. The urban sustainable development goal: Indicators, complexity and the politics of measuring cities. Cities 2017, 63, 92-97. [CrossRef]

49. Turban, E. Decision Support and Expert Systems: Management Support System, 4th ed.; Prentice Hall (Higher Education Division, Pearson Education): Upper Saddle River, NJ, USA, 3 February 1995.

50. Sainfort, S.; Gustafson, D.; Bosworth, K.; Hawkins, R.P. Decision Support Systems Effectiveness: Conceptual Framework and Empirical Evaluation. Organ. Behav. Hum. Decis. Process. 1990, 45, 232-235. [CrossRef] 
51. Kailiponi, P. Analyzing evacuation decisions using multi-attribute utility theory (MAUT). Procedia Eng. 2010, 3, 163-174. [CrossRef]

52. Scholz, M.; Franz, A.; Hinz, O. Effects of decision space information on MAUT-based systems that support purchase decision processes. Decis. Support Syst. 2017, 97, 43-57. [CrossRef]

Publisher's Note: MDPI stays neutral with regard to jurisdictional claims in published maps and institutional affiliations.

(C) 2020 by the authors. Licensee MDPI, Basel, Switzerland. This article is an open access article distributed under the terms and conditions of the Creative Commons Attribution (CC BY) license (http://creativecommons.org/licenses/by/4.0/). 